\title{
NSAIDs - Associated Damage to the Stomach Mucosa (Experimental Study)
}

\author{
Trubitsyna IE* and Varvanina GG \\ Department of Health in Moscow, Russia
}

ISSN: 2637-7632

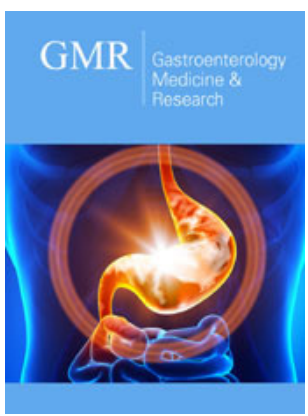

*Corresponding author: Trubitsyna IE, State budgetary institution of health care Moscow Clinical Scientific Center named after AS Loginova, Department of Health in Moscow, Russia

Submission: 戝 October 01, 2019

Published: 㭗October 15, 2019

Volume 3 - Issue 5

How to cite this article: Trubitsyna I, Varvanina G. NSAIDs - Associated Damage to the Stomach Mucosa (Experimental Study). Gastro Med Res. 3(5). GMR.000572. 2019.

DOI: 10.31031/GMR.2019.03.000572

Copyright@ Trubitsyna IE, This article is distributed under the terms of the Creative Commons Attribution 4.0 International License, which permits unrestricted use and redistribution provided that the original author and source are credited.
Keywords: NSAIDs stomach; Motility; Secretion; Damage

\section{Summary}

NSAIDs remain dangerous drugs due to the damaging effect on the mucous membrane of the stomach, intestines. Experimental studies were conducted to study the damaging effects of nimesulide and lornoxicam. It was found that these drugs damage the mucous membrane of the stomach. a non-selective drug has a slightly greater damaging effect. The damaging effect of these drugs enhances motor impairment, a decrease in $\mathrm{pH}$, and an increase in secretion volume. NSAIDs often lead to the formation of acute ulcers of the gastrointestinal mucosa. The development of NSAID-associated ulcerative lesions is due to an imbalance between the factors of defense and aggression in Summary non-steroidal anti-inflammatory drugs Summary nonsteroidal anti-inflammatory drugs the mucous membrane of the gastrointestinal tract $[1,2]$. AIM of our research was to establish factors that contribute to the development of NSAIDassociated ulcerative lesions of the gastric mucosa.

\section{Material and Methods}

The experiments were carried out on white Wistar rats of both sexes, weighing 190-210g. Before the operation, food was taken away for 18 hours with free access to water [3]. Under ether anesthesia, a laparotomy was performed and the pylorus was ligated, the drug solution was administered through the probe - experimental groups: Nimesulide - experiment 1 (01) and Lornoxicam - experiment 2 (O2), $\mathrm{pH}$ of the solutions of the injected drugs $=4.0-4.5$, volume $-1,0 \mathrm{ml}$, dose $-15 \mathrm{mg} / \mathrm{kg}$, the solution was shaken before administration. Control (C) - ligation of the pylorus and the introduction of $1.0 \mathrm{ml}$ of physiological saline. Autopsy after 2 hours, the animals were opened under ether anesthesia, and the abdominal cavity was examined. The $\mathrm{pH}$ and volume of the gastric contents were measured. Then using a magnifying glass examined the mucous membrane. Damage Index (ID), the total score of the identified lesions was calculated and divided by the number of animals. Points: edema=1; hyperemia $=2$; single hemorrhages $=3$; hemorrhages fused $=4$; erosion $=5$; ulcer $=6$.

\section{Results and Discussion}

C-The stomach is not stretched, the vascular pattern is slightly enhanced, which is visible through the serous membrane, the serous membrane is smooth, shiny. Gastric contents volume $2.0 \pm 0.15 \mathrm{ml} ; \mathrm{pH}=2.0 \pm 0.1$. Mucous membrane of the stomach: shiny, folding of the body and antrum preserved, in 2 animals swelling of the mucous membrane of the body, in one rat hyperemia in the body of the stomach. PI $=0.8 \pm 0.03 .2 .01$. - Nimesulide, $100 \mathrm{mg} /$ $\mathrm{kg}, 1.0 \mathrm{ml}$, through an autopsy probe, the stomach is stretched moderately, filled with light colored gastric contents. The vessels are translucent through the serous membrane, dilated, the vascular pattern is strengthened due to venous stasis. Gastric contents $-3.4 \pm 0.35 \mathrm{ml}$; $\mathrm{pH}=2.0 \pm 0.2$. The mucous membrane is opaque in the body area, hyperemic, edematous in all animals, hemorrhage in one animal. PI $=3.6 \pm 0.48 .3 .02$. Lornoxicam $-8 \mathrm{mg} / \mathrm{kg}, 1.0 \mathrm{ml}$, through an autopsy probe - the stomach is distended. The coffee grounds are filled with gastric contents. The vessels are dilated, the vascular pattern is strengthened due to venous stasis. Gastric contents - volume $5.6 \pm 0.4 \mathrm{ml}, \mathrm{pH}=1.5 \pm 0.1$. The mucous membrane in the body 
of the stomach is hyperemic, swollen. Fused hemorrhages. At the border of the body and antrum of the stomach, bleeding erosion and an acute ulcer, in the bottom of which there is a blood clot. PI $=6.8 \pm 0.84$. A high direct correlation was observed between gastric distension and PI ( $r=-0.884, p<0.05)$, and the inverse relationship between the $\mathrm{pH}$ of the gastric contents and PI $(\mathrm{r}=0.996, \mathrm{p}<0.05)$.

\section{Conclusion}

A decrease in $\mathrm{pH}$ and impaired gastric motility are factors that enhance the damaging effect of NSAIDs. Postoperative atony, diabetes mellitus, taking medications. The use of NSAIDs in this group of patients may be accompanied by an increased risk of developing unwanted lesions from the gastrointestinal mucosa, which affects the patient's quality of life $[4,5]$.

\section{References}

1. Drozdov VN, Tkachenko EV, Varvanina GG, Trubitsyna IE (2007) An experimental study of the effect of NSAIDs on the content of prostaglandins. Eksp Klin Gastroenterol (5): 77-80.

2. Tanaka A, Araki H, Hase S, Komoike Y, Takeuchi K, et al. (2002) Upregulation of COX-1 in the rat: A key to NSAID-induced gastric injury. Aliment Pharmacol Ther 16: 90-101.

3. Narita T, Okabe N, Hane M, Yamamoto Y, Tani K, et al. (2006) Nonsteroidal anti-inflammatory drugs induce hypermotilinemia and disturbance of inter-digestive migrating contractions in instrumented dogs. J Vet Pharmacol Ther 29(6): 569-577.

4. Botting RM (2006) Inhibitors of cyclooxygenases: Mechanism, selectivity and uses. J Physiol Pharmacol 57: 113-124.

5. Khanapure SP, Garvey DS, Janero DR, Letts LG (2007) Eicosanoids in inflammation: Biosynthesis, pharmacology, and therapeutic frontiers. Curr Top Med Chem 7(3): 311-340. 